\title{
Pneumococcal antigen in pneumonia. A post-mortem study with the histological and bacteriological findings
}

\author{
M. EL-ReFAIE \\ M.B., D.M.Sc. \\ C. DulaKe* \\ M.B., M.R.C.Path., Dip. Bact.
}

\author{
R. TAIT \\ M.B., B.A.O. \\ F. E. Dische \\ M.D., M.R.C.P., F.R.C.Path.
}

Public Health Laboratory, Dulwich Hospital, and Department of Morbid Anatomy, King's College Hospital

\section{Summary}

Pneumococcal capsular antigens can be detected in lung tissue by counter-current immunoelectrophoresis even when, following antibiotics, post-mortem bacteriology suggests that Escherichia coli has replaced pneumococci.

The results suggest that antipneumococcal therapy would benefit at least $55 \%$ of patients critically ill with lung infection and that the potentially toxic drugs directed at coliform bacteria may be unnecessary.

\section{Introduction}

Pneumonia is a common condition in seriously ill patients and is a frequent cause of death. Since the introduction of antibiotics, post-mortem lung studies have shown a striking change in the bacteriology of terminal pneumonia. The pneumococcus, formerly the pathogen isolated from most post-mortem lung cultures (Smillie and Duerschner, 1947), is rarely isolated nowadays, instead other bacteria, mainly coliform bacilli, are found (Kneeland and Price, 1960; Tanner et al., 1969). Clinicians now regard these as important lung pathogens, and patients are often treated with potentially toxic chemotherapeutics. How much of the change in the bacteriology of terminal pneumonia is of importance has not been proved.

Since the pneumococcus causes lung inflammation and is suppressed by antibiotic therapy, detection of its capsular antigen may be taken as evidence of infection by the organism (El-Refaie and Dulake, 1975). In this study, the role of the pneumococcus in terminal pneumonia is re-assessed; the technique of counter-current immunoelectrophoresis has been applied to a series of post-mortem lungs

\footnotetext{
* Correspondence: Dr C. Dulake, Public Health Laboratory, Dulwich Hospital, East Dulwich Grove, London S.E. 22.
}

and the presence of pneumococcal capsular antigen has been correlated with the histological and bacteriological findings.

\section{Materials and methods}

Post-mortem examinations

Forty-five post-mortems, performed at King's College and Dulwich Hospitals during the period January-March, 1975, were studied. Post-mortem examinations were usually conducted within $24-48 \mathrm{hr}$ of death; ten were delayed for $72 \mathrm{hr}$. The bodies were kept at $4^{\circ} \mathrm{C}$ until examined. Details of age, clinical findings, and antibiotic treatment during the patient's last stay in hospital, were extracted from the hospital records.

\section{Lung specimens}

In each case the lungs were carefully examined for areas of consolidation from which a piece (approximately $10 \mathrm{~g}$ ) was removed under aseptic precautions. Patchy consolidation was a common finding; and healthy as well as affected tissue might be contained in the pieces removed. When there was no apparent consolidation, a sub-pleural piece was taken from the lower lobe. Lung specimens were studied histologically and bacteriologically and tested for pneumococcal capsular antigen.

\section{Culture}

Precautions were taken to reduce surface contaminants before culture. The lung specimen was first washed with sterile saline, placed in boiling water for $10 \mathrm{sec}$, and then ground in a sterile tube and plated on blood agar, chocolate blood agar, and MacConkey's agar. The plates were incubated aerobically overnight at $37^{\circ} \mathrm{C}$; chocolate blood agar plates being in $10 \%$ carbon dioxide atmosphere. Organisms were identified using the methods of Cowan and Steel (1965). Scanty growth of saprophytic species (less than 10 colonies/plate) was ignored. 


\section{Counter-current immunoelectrophoresis (CIE)}

CIE was carried out in $1 \%$ agarose using a discontinuous veronal-acetate buffer system (El-Refaie and Dulake, 1975). Ground lung tissue was boiled in $2 \mathrm{ml}$ of sterile water for $15 \mathrm{~min}$, then centrifuged and the supernatant tested. Danish antisera were used (Lund, 1963); and all bacterial isolates were carefully tested for the production of cross-reacting antigens.

\section{Results}

There were forty-three adults (average age 65 years), one infant, and a still-born fetus. Cardiovascular disease was present in nineteen cases, malignant tumour in fifteen, renal and liver failure each in three cases, and rheumatoid arthritis, peritonitis and acute gasteroenteritis in the remaining five. More than two-thirds of the adult patients had had antibiotics during their illness.

Table 1 lists the organisms isolated from inflamed and non-inflamed lungs. In both cases the growth was usually mixed and, in thirty of thirty-eight instances, formed mainly of coliform bacilli. Most of the species were equally distributed between both groups. There was no pneumococcal growth; and sterile cultures were found in nineteen instances, eight of them from cases with inflammation.

Table 2 shows the results of the histological examination of lung specimens and correlates these with the finding of pneumococcal capsular antigen.
The presence of the antigen correlated with pneumonia: eleven of fourteen antigen-positive specimens showed acute pneumonic inflammation.

Table 3 gives details of the cases with antigenpositive lung specimens. A total of twenty-one types of capsular antigen was identified. Types 3 and 32 were found more commonly and each was present in three specimens. In general, capsular types 1-10 inclusive were less frequently encountered than types 11-48; the latter represented $67 \%$ (fourteen of twenty-one) of the types identified. Cross-reaction was observed only once between type 41 and a strain of Escherichia coli in case 45.

\section{Discussion}

Using counter-current immunoelectrophoresis it was possible to identify the polysaccharide capsular antigen of the pneumococcus in $55 \%$ (eleven of twenty) of lungs showing histological evidence of acute pneumonia. The presence of occasional polymorphs in one of the specimens showing chronic inflammatory changes may indicate a recent pneumonic process. It appears, therefore, that the incidence of pneumococcal terminal pneumonia determined by antigen detection is $60 \%$.

The presence of the antigen correlated strongly with pneumonia (Table 2). The finding of the antigen in one of the twenty specimens without inflammation probably represents a spill-over of the antigen from a nearby undetected pneumonic focus or can be

TABLE 1. Bacteriological and CIE findings in forty-five unselected post-mortem lung specimens

\begin{tabular}{|c|c|c|}
\hline \multirow[b]{2}{*}{ Findings } & \multicolumn{2}{|c|}{ Lung inflammation } \\
\hline & Present (twenty-five cases) & Absent (twenty cases) \\
\hline $\begin{array}{l}\text { Bacterial growth * } \\
\text { E. coli } \\
\text { Klebsiella spp. } \\
\text { Enterobacter aerogenes } \\
\text { Proteus spp. } \\
\text { Strep. faecalis } \\
\text { Staph. aureus } \\
\text { Staph. albus }\end{array}$ & $\begin{aligned} 11 & (44 \%) \\
2 & (8 \%) \\
2 & (8 \%) \\
4 & (16 \%) \\
2 & (8 \%) \\
2 & (8 \%) \\
1 & (4 \%)\end{aligned}$ & $\begin{array}{ll}6 & (30 \%) \\
0 & (0 \%) \\
3 & (15 \%) \\
2 & (10 \%) \\
1 & (5 \%) \\
1 & (5 \%) \\
1 & (5 \%)\end{array}$ \\
\hline No bacterial growth & $8(32 \%)$ & $11(55 \%)$ \\
\hline Pneumococcal antigen & $13(52 \%)$ & $1(5 \%)$ \\
\hline
\end{tabular}

* Mostly from mixed culture.

TABLE 2. Correlation of histology with pneumococcal antigen in forty-five unselected post-mortem lung specimens

\begin{tabular}{lcc}
\hline Lung histology & Antigen present & Antigen absent \\
\hline Acute pneumonia (twenty cases) & 11 & 9 \\
Chronic inflammatory changes * (five cases) & 2 & 3 \\
No evidence of inflammation (twenty cases) & 1 & 19 \\
Total (forty-five cases) & 14 & 31 \\
\hline
\end{tabular}

* Chronic inflammatory cells with or without fibrosis. 


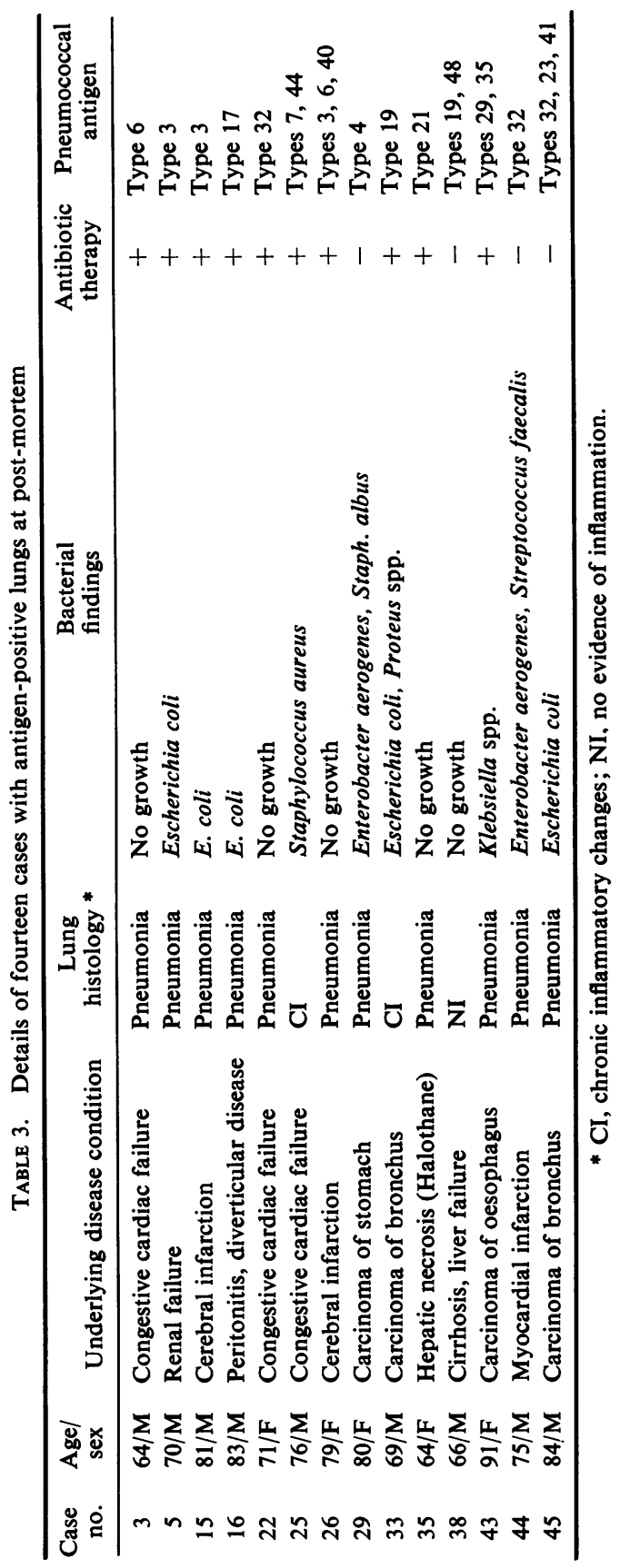


attributed to the inclusion of healthy tissue in the histologically studied lung specimens.

Two points had to be considered in interpreting the findings. Firstly, it might be antigen derived from commensal pneumococci that was being detected. However, the results show the close association between lung inflammation and the presence of the antigen indicating the discriminant nature of the technique used. Secondly, antigenic overlap occasionally occurs between coliform bacteria and pneumococci. Evidence of cross-reactions was observed only once between antigen type 41 and a strain of E. coli in case 45 (Table 3).

In this study, the presence of more than one capsular antigen in five of the inflamed lungs can be explained by the carriage of more than one pneumococcal serotype in the throat, a well known phenomenon (Straker, Hill and Lovell, 1939), and the enhanced pathogenicity of such strains which occurs in the presence of debilitating illness. The isolation of more than one pneumococcal serotype from patients dying from pneumonia has been observed by earlier workers (Grist, Landsman and Anderson, 1952; Page and Lunn, 1973).

Immersion of autopsy tissue in boiling water for removal of surface contaminants has been followed by Foster (1966) and by a Public Health Laboratory Service Working Party (unpublished). Pure growths of pneumococci have been isolated in the Dulwich Hospital laboratory on three occasions from consolidated lung tissue (not in this series) indicating that immersion of the lung specimen in boiling water for $10 \mathrm{sec}$ kills only surface bacteria while those in the depths of the infected tissue are unaffected.

The key to the failure of isolating pneumococci from lungs is prior antibiotic therapy which is also responsible for modifying autopsy bacteriology. The following case report illustrates this fact.

Case 15. An 81-year-old man was admitted on 8 February 1975 with left-sided hemiparesis and bronchopneumonia. He was immediately given 'Ampiclox' 500 mg, 6-hourly. On 9 February 1975 a culture of sputum yielded no significant pathogens. Types 3 and 8 pneumococcal antigens were detected in the sputum. The patient died that evening. A post-mortem was performed on 10 February 1975; from the consolidated lung tissue a pure growth of $E$. coli was obtained and type 3 capsular antigen was identified (Table 3).

Undoubtedly, the lung damage observed is caused by pneumococcal infection and the $E$. coli played no active part in the infection or at most invaded already damaged tissue.

In addition to prior antibiotic therapy, changes in the body flora occurring shortly before or after death may modify the bacterial picture of post-mortem lung cultures. The present data (Table 1) and those of earlier workers (e.g. Kneeland and Price, 1960) show that $E$. coli can be isolated from normal lung tissue at post-mortem.

In conclusion, the study suggests that pneumococcal lung infection in patients with chronic or systemic disease is as important today as it was before the introduction of antimicrobials and that post-mortem bacteriology is highly questionable in assessing the role of different lung pathogens.

\section{Acknowldegments}

We should like to thank Professor A. C. Cunliffe and Mr C. H. Collins for helpful suggestions, and the technical staff of Dulwich Hospital for their assistance and co-operation.

This work is supported by a grant from the Egyptian Government.

\section{References}

Cowan, S.T. \& Steel, K.J. (1965) Manual for the Identification of Medical Bacteria. Cambridge University Press.

El-Refaie, M. \& Dulake, C. (1975) Counter-curreng $\vec{\bullet}$ immunoelectrophoresis for the diagnosis of pneumoe coccal chest infection. Journal of Clinical Pathology, 28 801.

FOSTER, W.D. (1966) The bacteriology of necrotizing jejunitis in Uganda. East African Medical Journal, 43, 550.

Grist, N.R., LANDSMAN, J.B. \& ANDERSON, T. (1952) Studies in the aetiology of pneumonia in Glasgow. Lancet, i, 640.

Kneeland, Y. \& Price, K.M. (1960) Antibiotics and terminal pneumonia. American Journal of Medicine, 29, 967.

Lund, E. (1963) Polyvalent diagnostic pneumococcus sera. Acta pathologica et microbiologica scandinavica, 59, 533.

PAGE, M.I. \& LUNN, J.S. (1973) Pneumococcal serotypes associated with acute pneumonia. American Journal of Epidemiology, 98, 255.

SMillie, W.G. \& Duerschner, D.R. (1947) The epidemiology of terminal bronchopneumonia. I. The significance of post-mortem cultures in determination of the etiology of terminal pneumonia. American Journal of Hygiene, 45, 1.

Straker, E., Hill, A.B. \& Lovell, R. (1939) A study of the nasopharyngeal bacterial flora of different groups of persons observed in London and South-East England during the years 1930 to 1937. Report of Ministry of Health, London, No. 90.

TANNER, E.I., Gray, J.D., Rebello, P.V.N. \& Gamble, D.R. (1969) Terminal bronchopneumonia. A bacteriological and histological study of 111 necropsies. Journal of Hygiene, Cambridge, 67, 477. 